\title{
Creating Less Disastrous Disasters
}

\author{
Maria Carmen Lemos and Emma L. Tompkins
}

\begin{abstract}
1 A two-tiered approach to disaster management For decades, the disaster literature has called attention to the dual character of climate-related risk. On the one hand is the level of exposure to the hazard (the storm, the flood, the drought, etc.), and on the other hand is the vulnerability of different socioeconomic systems to the effects of different natural hazards. To address this vulnerability, some form of risk management can currently be found in most countries of the world, although the efficacy of the risk management systems varies widely. Political ecologists and others have long advocated that responding to climate risk should include both short-term disaster risk response - that is, action to prepare for and recover from the immediate effects of disaster (e.g. early warning systems) and structural reforms that seek to address the factors that define people's vulnerability to disasters to begin with (poverty, lack of education, etc.). Calls for better policy design and implementation at these two levels are not new. Yet after 20 years, it is surprising that more research has not tried to understand why the bulk of responses to disasters to date have failed to account for both sides of the vulnerability equation.
\end{abstract}

Our lack of understanding on why disaster risk reduction has not fared better historically becomes even more critical when we consider the expected impacts of climate change on the exposure and adaptive capacity ${ }^{1}$ of human systems. Adaptation defined as the amount of (potential) damage caused to a system by a particular climate-related event or hazard - if successfully designed and implemented should result in an equal or improved situation (when compared with the initial condition). Unsuccessful adaptation occurs when the outcome situation is worse than before. The latter is frequently the case when poor countries and the poor within these countries have barely recovered before the next storm or drought hits.
The compounding effects of repeated climaterelated hazards makes it almost impossible to avoid and break the cycle of successive inadequate or inappropriate adaptation. The ability of different actors, organisations and systems to break this cycle hinges specifically on their level of adaptive capacity. Given the large uncertainty in scenarios of future climate change and their contextual character, it makes more sense to focus on building adaptive capacity than specific adaptations, through identifying and characterising the attributes necessary to make these adaptations successful. While all adaptation is local, adaptive capacity is not. Generalisations can be made across the divide between disaster risk reduction and 'deeper' structural reform to promote risk management that contributes to social transformation.

Considerable effort has been made in the literature to theorise what attributes may enhance the capacity of human and sociopolitical systems to prepare for and recover from negative impacts of climate-related phenomena (Smit et al. 2000; Folke et al. 2002; Tompkins and Adger 2005; Eakin and Lemos 2006). Yet, there have been relatively few empirical studies that seek to understand how this capacity can or has been built (or not) in the real world. What factors make human, social and political systems less vulnerable to climate-related phenomena? We argue that building adaptive capacity is a two-tiered process that must include both risk management to climate impact and deeper level socioeconomic and political reform that addresses the root causes of vulnerability, especially among the vulnerable poor.

Tier one comprises the design and implementation of risk management institutions - such as disaster preparedness plans, early warning systems and emergency disaster relief - that can potentially mitigate the most immediate and egregious effects 
of climate-related impact, especially among the poor in society without the capacity to self-rescue. Tier two encompasses socioeconomic and political reform that addresses the range of inequalities at the root of differential vulnerabilities that keep the poor living in poverty. Reforms such as income redistribution, land reform, universal education and healthcare access, and political democracy are just a few that might be necessary to decrease poverty and vulnerability in less developed countries. Although these kinds of reforms have been on the development agenda for a long time, their povertyreducing benefits have proved elusive to most poor countries in the world. The threat of climate change as an emergent stressor that will exacerbate vulnerability makes their implementation more urgent.

Beyond the state - but certainly not without it - this two-tiered process must involve a broad number of institutions within the state-private-community continuum as well as across different scales of decision-making (Lemos and Agrawal 2006; Dodman and Satterthwaite, this IDS Bulletin). On the one hand, the kind of deep transformation needed to address inequalities that perpetuate vulnerability among the poor has historically been economically, socially and politically too costly for most governance systems to tackle and the daunting character of its implementation may be intimidating at best and paralysing at worst. On the other hand, aiming at deeper transformation does not have to be an all or nothing proposition.

One way to spearhead change is to identify which, among risk management actions currently in place, can be more or less conducive to create the conditions for structural reform. Moreover, because these are not discrete processes, action in one tier can affect and be affected by action in another, in a way that creates a positive synergy between them. Hence, it is important to identify how risk management institutions can contribute not only to building adaptive capacity to specific climate-related hazards but also to decreasing overall vulnerabilities among groups at risk. For example, by subscribing to risk management approaches that create positive synergies across the state-society divide, drought response planning, hurricane preparedness, or water management, institutions may create the conditions to build longer-term adaptive capacity among vulnerable groups.
Approaches that are inclusionary (participatory), accountable, transparent and democratic, may be more conducive to the creation of an empowered citizenry better equipped to break free from clientelist systems and to mobilise for social reform. Similarly, approaches that integrate risk management with sustainable natural resources use and adaptive governance may be more conducive to social learning and to building adaptive capacity and social capital than top-down approaches that insulate decision-making from stakeholders (Lemos 2007).

\section{Two vulnerable regions, two tales of success}

In this article, we draw on previous empirical research in the Cayman Islands in the Caribbean and Ceará in NE Brazil to highlight the fundamental components that underpin the creation of adaptive capacity (Lemos et al. 2002; Tompkins and Hurlston 2003; Lemos 2003; Tompkins 2005; Lemos 2007). ${ }^{2}$ Both sites have been historically vulnerable to climate variability and extremes (tropical cyclones in the Cayman Islands and drought in NE Brazil) and their evolving response to these climate-related hazards over many years may offer the best analogue available to understand how capacity can be built to transform society through disaster risk reduction that addresses vulnerability and builds adaptive capacity to climate change.

The Cayman Islands are one of the wealthiest Caribbean islands, with a per capita GDP of US\$33,700 in 1997, with financial services and tourism providing the backbone to the country's economy. The three islands cover 102 square miles, have a population of approximately 43,000, and are a UK Overseas Territory. Ceará, in contrast, is one of the poorest states in Brazil, with a population of 7 million and over 90 per cent of its territory is semi-arid. Until recently, drought response in Ceará has been characterised by the infamous 'drought industry', that is, the corrupt misappropriation and misuse of public funds earmarked for drought-relief (Lemos et al. 2002). Two traditional approaches to risk management have been particularly clientelismprone: the implementation of emergency response and the construction of extensive waterworks to store and move water, including the creation of work fronts and the distribution of food baskets and water trucks to communities in distress. All these activities were often subject to corruption and abuse; for example, it was common for politicians to exchange votes for placement in the work fronts or food basket programmes. 
For the past 30 years both regions have experienced rapid socioeconomic progress, although Ceará remains a highly unequal society (Lemos 2007). Whereas the two regions differ considerably in GDP per capita, wealth distribution, physical characteristics, politics and culture, we find that their path to reduce vulnerability to hazards has much in common. We suggest that if it is possible to identify common markers of successful transformation in such distinct policy environments, then maybe such markers can be generalisable to a wide variety of environments, especially in less developed regions of the world.

In comparing the two sites, we find that four factors were critical to improving disaster management in both cases (Tompkins et al. 2008). First, the agencies and organisations responsible for disaster management were flexible, able to learn from past success and/or failure and to build on their relationship with stakeholders to push forward the policy agendas and their implementation. Second, a group of committed, reform-minded and politically active actors in the public (in NE Brazil) and in the public and private sectors (in the Cayman Islands) championed a series of changes that addressed critical needs (i.e. shelter and emergency supplies for those in poorly constructed homes in the Cayman Islands and employment and income for those affected by drought in Brazil) and lent the nascent institution credibility and political feasibility. Third, these organisations and individuals sought to integrate disaster management into other policy processes, creating an approach to disaster management that was much better suited to the changing nature of social disasters and the many stressors beyond the physical hazard causing them. Fourth, in both cases there was a long-term commitment to investing in disaster risk management and in collaborative learning-based approaches to managing risk.

Through the years, and many disasters, flexible, learning organisations and stakeholder involvement have been a critical part of risk reduction and vulnerability reduction in the Cayman Islands and Ceará. Since the late 1980s/early 1990s, a confluence of positive factors - including political reform, government reorganisation, changes in government priorities and regulatory institutions - have enabled the National Hurricane Committee (NHC) in the Cayman Islands, and the state Civil Defence agency (CEDEC) in Ceará to achieve a much higher level of efficacy to build adaptive capacity to better manage hurricanes and drought respectively. ${ }^{3}$ While the $\mathrm{NHC}$ evolved from a committee of volunteer civil servants loosely organised by the government to a formalised, efficient, quasi-government management organisation, CEDEC was able, for the first time, to establish a centralised structure that coordinated the efforts from all areas of the state government to respond to drought. At the same time, both organisations actively sought to involve stakeholders in the design of their risk reduction plans.

In the Cayman Islands, members of the NHC sit on the various committees that advise the government on long-term planning (such as the Central Planning Authority that allocates planning approval). Annually, leading actors in the different economic sectors and government departments get involved in planning for the next hurricane season. Among the islanders, there is a strong perception of social interdependence and a staunch belief in collective action as the way to ensure support for all sections of society. Inclusion of all government departments, private firms, churches, non-governmental organisations (NGOs), primary care agencies, community leaders and charitable organisations ensures that all members of society are considered in hurricane planning, and that the most vulnerable are identified and prioritised in annual planning. This level of inclusion also means that there is a strong support network throughout the islands, reinforced year after year as different communities, sectors, businesses and government agencies find that they are either affected by a hurricane or involved in the response and clear up (Tompkins 2005).

In Ceará, the new approach to drought response was also marked by the use of inclusive committees. CEDEC created community-based committees COMDECs (Comitê de Defesa Civil) - to identify and rank the families of each community according to need. The committees included representatives of several sectors of society such as the Church, rural labour unions, city council representatives, landowner associations, state officials, and professional associations. The COMDEC's generated lists were then prioritised within the municipio and used as a basis for the distribution of jobs, food baskets and water trucks. CEDEC also introduced a state-wide ranking of municípios affected by drought based on 'techno-scientific criteria', which institutionalised the declaration of drought emergency outside the purview of local politicians (Lemos 2003). These 
changes were not an isolated event but part of much broader reforms that sought to transform and modernise the state. ${ }^{4}$ In the process, Ceará transitioned from a staunch political oligarchy to a more democratic regime where Brazil's reformoriented politicians have experienced surprising success. Maybe the most critical outcome of the new system has been the attempt to break with the vicious cycle of drought and clientelism in which the survival of traditional politics is predicated on the persistence of drought and its impacts - that is, only by keeping their electorate vulnerable to drought can politicians guarantee their bargaining power in time of elections. In this context, it is not surprising that politicians may have strong incentives to keeping the cycle of poverty and vulnerability intact.

As a result, in addition to the COMDECs, new avenues for civil society participation in droughtrelated planning at the local level have been created, including participatory vulnerability mapping at the município level (Nelson 2005) and river basin committees (Lemos 2007). However, the ability of the very poor to participate in these fora has been mixed. While overall there certainly are more opportunities for inclusion, the level of actual participation of the poorest segments of the Ceará population has been low (Taddei 2005).

Nevertheless, these participatory mechanisms represent progress in enhancing benefits to the poor when compared with past drought policies.

Learning from successes and failures of past years has been an integral feature of the response strategy of both the NHC and CEDEC. In the Cayman Islands, at the end of every hurricane season, the $\mathrm{NHC}$ reviews what it has done effectively the year before and what has not worked - in the past failures have included slow restoration of power to remote communities, or inadequate provision of medical and food supplies in the district shelters. Lessons learned after each season are incorporated into existing hurricane plans (in each and every government department and agency), with a view to improving hurricane response the following year. This process requires active identification of the most vulnerable, i.e. those who were not adequately protected during the storms. As a result of the integration of disaster risk reduction in wider government planning processes, such knowledge also feeds into social planning, for example care for the elderly.
In Ceará the current system is the result of many different incarnations of disaster management to which incremental changes have been implemented. For instance, the agency has been able to learn from past failure to improve response to drought. However, organisational flexibility is higher in the Cayman Islands than in Ceará. Whereas the NHC has been able to review its composition (to ensure it maintains the appropriate membership), its structure and network arrangements, its funding allocation, and its responsibilities after each disaster, CEDEC, as a bureaucratic agency has been much less flexible. For example, although managers would very much like to adopt a more preventive disaster programme, the agency is unable to move funds around in its budget and many times have had to wait for a crisis to be able to access earmarked funds. In contrast, the $\mathrm{NHC}$ has discretion to design and implement new initiatives to reduce risk. This feature is built in to disaster risk reduction policy and allows decisionmakers to make adjustments and take politically motivated actions. Whereas this can be harmful in places where corruption may be prevalent (such as Ceará) decision-makers in the Cayman Islands, as with other Caribbean island states, assume that the advantages of flexibility outweigh its disadvantages (Pugh 2006). This is particularly true in terms of being able to use political capital for setting development priorities or pushing forward long-term planning goals.

In this context, the role of committed civil servants has been pivotal for policy success. In the Cayman Islands, members of the NHC are highly motivated,

enthusiastic and trusted civil servants who were seen to be investing time and energy beyond what was required to improve hurricane planning in the islands. The strong, influential and well-respected chair of the $\mathrm{NHC}$ worked diligently to raise the profile of hurricane risk within the government. The inclusion of representatives of groups, such as the churches and members of social services, with a remit to care for the poor and the vulnerable, guaranteed that the $\mathrm{NHC}$ addressed the needs of the broad cross-section of the Cayman Islands society, thereby strengthening the ground-roots support for the Committee.

In Ceará CEDEC's reform-oriented managers were equally committed to change their disaster management. Many of these managers had been trying for years to reform disaster management and the emergence of a progressive state governor gave 
them the first real opportunity at galvanising political capital to push for reform (Tendler 1997; Lemos 2003). However, CEDEC's new approach was not without fierce resistance and the managers faced strong local opposition (Lemos 2003). By using a 'technical' approach to drought relief these managers were able to insulate their decisionmaking process from politics and protect public resources. Their insistence that the COMDECs included representatives from organisations committed to the poor, such as the Church and labour unions, may also have diluted politicians' dominance at the local level despite the persistence of clientelism, especially during drought emergency (personal communication 2002).

Moreover, managers and organisations in both cases sought to integrate disaster management with other policies and to implement long-term disaster policy. While in Ceará, the results of such integration have been mixed (Lemos 2007), the Cayman Islands fared much better (Tompkins 2005). In Ceará, several attempts to create a formal integrated structure have mostly failed in practice (Carvalho et al. 1993), with many programmes not succeeding beyond their planning phase (Lemos 2007). At the national level however, there have been the creation of integrated anti-poverty programmes, such as the Bolsa Familia (a monthly cash voucher for poor families) that may critically shape local level vulnerability to drought.

The Cayman Islands' government has mainstreamed disaster risk reduction by embedding risk management into all areas of policymaking. Long-term risk management is incorporated through integrated land use planning. The Development and Planning Committee within the Cayman Islands' government requires participation from all government departments to ensure that plans rolled out achieve the broader objectives of the Cayman Islands' government. While all parties do not necessarily agree with all elements within these plans, the process of decision-making is essentially an integrated, crossdepartmental one that strives to tie in with the overall national structure, that incorporates principles of disaster risk reduction and that focuses on long-term social and economic development.

In both places, the reliance on these four markers of good governance has decidedly increased the positive returns from disaster management. Despite the fact that much higher levels of poverty and inequality in NE Brazil have resulted in much slower progress in decreasing general vulnerabilities, the steadfast move from a clientelist and insulated disaster management response to a more democratic, participatory and inclusionary one has resulted in palpable gains for the poor in times of climate-related crisis (Lemos 2003; Lemos 2007; Nelson and Finan 2007). Although there is a long way to go, the experience in the Cayman Islands, and in NE Brazil, suggest that a concerted pursuit of disaster risk reduction policies that seek at the same time to address deeper inequalities, can critically affect overall vulnerabilities, particularly among the poorest segments of the population.

\section{Two tiers, one goal}

While progress in disaster risk reduction has been well documented and broadly positive, the history of addressing the structural inequalities at the root of socioenvironmental vulnerabilities has been much less positive. Not surprisingly deeper structural transformation is not easy to implement either economically or politically, as decades of failed development and anti-poverty interventions demonstrate. In both cases studied in this article, we find that the presence of the four factors for effective risk reduction (flexible, learning-based, responsive governance; committed, reform-minded and politically active actors; disaster risk reduction integrated into other social and economic policy processes; and a long-term commitment to managing risk) have improved response to disaster even if the outcome in the NE Brazil case has fallen short of the magnitude needed. By choosing to focus on these four factors, we intentionally pursue a higher level of generalisation that hopefully can be relevant to other regions and case studies beyond the two we target here, especially systems that are increasingly vulnerable to global climate change. We believe that looking at how systems and groups respond to climate variability-driven stress can inform future policy focusing on prevention and response to a changing climate.

This approach to drought response has come a long way from the clientelism-infested actions of the past and reflects a synergistic dynamic between socioeconomic and political reform and risk reduction. While there is still much to do in Ceará to reduce drought vulnerability, significant progress has been achieved in relation to 'traditional' disaster management. We also found that by incorporating 
well-tested good governance practices in disaster risk reduction, especially the involvement of stakeholders committed to improving the lot of the poorest and most marginalised along with more open and democratic decision mechanisms, both regions may have paved the way for deeper reform. In the Cayman Islands, the recognition of the need to include those least able to cope with storms contributed to a longer-term repositioning and reprioritisation of the poor in government planning. In the case of NE Brazil, the empowerment of local collective action structures may have both diluted elite dominance and

\section{Notes}

1 The IPCC defines adaptive capacity as 'the ability of a system to adjust to climate change (including climate variability and extremes), to moderate potential damages, to take advantage of opportunities, or to cope with the consequences' (IPCC 2001: 928).

2 Research for the Ceará case has been funded by grants from the National Science Foundation (Award \#SES 0233961) and the National Oceanographic and Atmospheric Administration (Award \#NA03OAR4310010). Field research has been made in separate field campaigns carried out during 2000-05 and included over 70 in-depth interviews with policymakers (disaster managers, water managers and extension agents)

\section{References}

Carvalho, O.; Egler, C.; Antonio, G.; Mattos, M.; Maria, C.L.; Barros, Helio; Fé, Jose de Anchieta and Mouraand Nobre, Carlos (1993) Variabilidade Climática e Planejamento da Ação Governamental no Nordeste semi-árido - Avaliação da Seca de 1993 [Climate Variability and Governmental Action Planning in the Semi-Arid Northeast - Evaluation of the 1993 Drought] (Final Report). Brasilia: Secretaria de Planejamento, Orçamento e Coordenação da Presidência da RepúblicaSEPLAN-PR, Instituto Interamericano de Cooperação para a Agricultura (IICA)

Eakin, Hallie and Lemos, Maria Carmen (2006) 'Adaptation and the State: Latin America and the Challenge of Capacity-building Under Globalization', Global Environmental Change 16.1: 7-18

Folke, C.; Carpenter, S.; Elmqvist, T.; Gunderson, L.; Holling, C. and Walker, B. (2002) 'Resilience and Sustainable Development: Building Adaptive constrained the most negative aspects of corrupt drought response. While these actions are not sufficient to spearhead structural reform, they may wear away the inequalities (social, economic and political) that shape vulnerability in less developed regions. To go even further, bridging institutions, such as the NHC in the Cayman Islands, linking disaster risk managers with the development planners are required to ensure that the palliative care offered by disaster risk reduction is not used as an alternative to deeper structural surgical reforms that may be needed to address the issues of inequality in society.

as well as the governor of the state and local level key informants. Research for the Cayman Islands case study was funded through a Tyndall Centre for Climate Change Research Fellowship. The research took place during 2002-05 and included over 70 interviews with the heads of government departments, leaders of industry, NGOs, community-based and faith-based organisations, and individuals,

3 For a detailed account of these changes, see Tompkins and Hurlston (2003) for the Cayman Islands case; and Lemos (2003, 2007) for the Ceará case.

4 For a detailed account of this transformation, see Tendler (1997).

Capacity in a World of Transformations', Ambio 31.5: 437-40

IPCC (2001) Working Group II Climate Change 2001: Impacts, Adaptation and Vulnerability, Geneva: Intergovernmental Panel on Climate Change

Lemos, Maria Carmen (2007) 'Drought, Governance and Adaptive Capacity in North East Brazil: $A$ Case Study of Ceará', in Fighting Climate Change: Human Solidarity in a Divided World, Human Development Report 2007/2008, United Nations Development Programme, Basingstoke: Palgrave Macmillan

Lemos, Maria Carmen (2003) 'A Tale of Two Policies: The Politics of Seasonal Climate Forecast Use in Ceará, Brazil', Policy Sciences 32.2: 101-23

Lemos, Maria Carmen and Agrawal, Arun (2006) 'Environmental Governance', Annual Review of Environment and Resources 31: 297-325

Lemos, Maria Carmen; Finan, T.; Fox, R.; Nelson, D and Tucker, J. (2002) 'The Use of Seasonal 
Climate Forecasting in Policymaking: Lessons from Northeast Brazil', Climatic Change 55.4: 479-507

Nelson, D.R. (2005) 'The Public and Private Sides of Persistent Vulnerability to Drought: An Applied Model for Public Planning in Ceará, Brazil', PhD dissertation, Department of Anthropology, University of Arizona, Tucson AZ

Nelson, Don, R. and Finan, Timothy, J. (2007) 'Persistent Vulnerability and Ironic Adaptation: The (False) Security of Drought in Ceará, Brazil', paper presented at the Society of Applied Anthropology Conference, 27-31 March, Tampa

Pugh, J. (2006) 'Physical Development Planning in the Anglophone Caribbean: The Re-articulation of Formal State Power', in J. Pugh and J.H. Momsen (eds), Environmental Planning in the Caribbean, Aldershot: Ashgate

Smit, B.; Burton, I.; Klein, R.J.T. and Wandel, J. (2000) 'An Anatomy of Adaptation to Climate Change and Variability', Climatic Change 45.1: 223-51

Taddei, R. (2005) 'Of Clouds and Streams, Prophets and Profits: The Political Semiotics of Climate and Water in the Brazilian Northeast', PhD dissertation, Graduate School of Arts and Sciences, Columbia University, New York Tendler, Judith (1997) Good Government in the Tropics, Baltimore MA: The Johns Hopkins University Press

Tompkins, Emma L. (2005) 'Planning for Climate Change in Small Islands: Insights from National Hurricane Preparedness in the Cayman Islands', Global Environmental Change 15: 139-43

Tompkins, Emma L. and Adger, Neil W. (2005) 'Defining Response Capacity to Enhance Climate Change Policy', Environmental Science and Policy 8.6: 562-71

Tompkins, Emma L. and Hurlston, L.A. (2003) Report to the Cayman Islands' Government. Adaptation Lessons Learned from Responding to Tropical Cyclones by the Cayman Islands' Government, 1988-2002, Norwich: Tyndall Centre for Climate Change Research, University of East Anglia Tompkins, E.L.; Lemos, M.C. and Boyd, E. (2008 in press) 'A Less Disastrous Disaster: Managing Response to Climate-Driven Hazards in the Cayman Islands and NE Brazil', Global Environmental Change 